\title{
Computer listing of the effects of drugs on laboratory data
}

\author{
D. S. YOUNG, D. W. THOMAS, AND R. B. FRIEDMAN \\ From the Clinical Pathology Department, Clinical Center, National Institutes of Health, Bethesda, \\ Maryland, USA
}

SYNOPSIS A listing of approximately 10000 effects of drugs on tests performed in clinical laboratories has been developed in a time-shared computer. The list contains a directory for matching proprietaryㅁㅇㅇ and generic names of drugs and an explanation for the mode of action of the drug on each test. N Each entry is supported by a bibliographical reference that contains the author's names, and thetitle of the article and journal. It is possible to search for specific 'character strings' (word or words, $\overrightarrow{0}$ number, etc) to obtain all the effects of a particular drug, or all drugs that affect a particular test, $\stackrel{\infty}{\oplus}$ or even to search for a specific explanation for an effect. The system is undergoing trial in the음 Department's own computer to permit of automatic correlation of the effects of drugs with laboratory data from patients in one hospital ward.

Modern medicine has been characterized both by an increase in the number of drugs administered to patients and also by an increase in the number of laboratory tests ordered. In this centre it is now quite common for a patient to receive as many as 10 different drugs at one time. Recently one patient received 43 different drugs during his hospital stay of three months. Twenty of these drugs were received during one critical phase of his illness. Nowadays 20 or more laboratory tests may be requested at the same time. Only recently have physicians considered the consequences of these trends on the interpretation of laboratory results.

It is now recognized that much effort is expended in hospitals in the treatment of iatrogenic disorders (Melmon, 1971). This increased economic burden on the patient and community may be attributable, in part, to unrecognized effects and toxicity of drugs. Although there is increasing evidence that many drugs affect laboratory tests (Garb, 1971; Hansten, 1971; Martin, 1971) leading to potential misinterpretations, Van Peenen and Files (1969) contend that the incidence of significant effects of drugs on laboratory tests is low. However, we have determined that day-to-day variation in the concentration of many blood constituents is small in normal subjects (Young, Harris, and Cotlove, 1971) and believe that many of the changes in concentration of blood constituents occurring in hospital patients may be due to the effect of drugs. With the increasing Received for publication 13 September 1972. precision of analyses now obtainable in clinical laboratories it should be possible to identify mose incidents of drug-induced modifications of laborat azy? data.

Many physicians are uncertain how to interprets these small changes. Most physicians are familiaro with the major effects on laboratory tests of drugso administered for specific purposes but many are $\stackrel{\mathbb{\Omega}}{\stackrel{\mathbb{2}}{2}}$ unaware of the side effects of drugs on other bio- $\overrightarrow{\vec{F}}$ logical functions. Few are aware of the analytical 3 methods used to determine the constituents in blood serum or the influence of drugs on these procedures.

To facilitate the interpretation of alterations in laboratory tests, we have developed a central file of? the effects of drugs on laboratory tests. This file is stored in a computer to permit rapid interrogation in response to telephone queries and to permito automatic correlation of tests requested with the drugs that are administered to different patients. $\frac{}{3}$ This approach allows continual updating as new effects are reported or analytical methods are changed. In this preliminary report, we describe the N structure of our computer listing of anticipated and unintended drug effects (Claude). Later reports will detail the role of the system in the automatic $\omega$ correlation of changes in laboratory tests with drugs administered to patients.

\section{Structure of a File for Interrogation and Editing}

The system for rapid retrieval of information from $\frac{\bar{\Phi}}{\circ}$ 984 
our drug/test interaction file is based on the Wylbur computer program developed by the Stanford University Computation Center and adopted for use at the central computer facility of the National Institutes of Health. Wylbur was designed to provide a comprehensive editing facility with prompt responses through typewriter terminals without interfering with other jobs being processed by the central computer. The editing facility of Wylbur allows the user to create, modify, store, and retrieve text on a line-by-line basis so that no other lines in the data set are affected. An especially useful attribute of the system is its ability to search for a particular 'character string' (word or words, number, etc) and to print at the terminal all lines in the data set in which this character string appears. Our information retrieval system was designed to exploit this capability.

The maximum length of the line of text is 120 characters, and was determined by the limitations of the size of the carriage of the existing typewriter. Thus, if all the information concerning a particular drug/test interaction is stored in a single 120character line, we can use the system's ability to search a particular character string to retrieve all entries that might include a specified drug, test, mechanism, etc. We therefore set up the information in our file as indicated in Table.

\begin{tabular}{|c|c|}
\hline Characters & Subject \\
\hline $1-19$ & Drug name \\
\hline \multirow[t]{7}{*}{20} & Code for sample type \\
\hline & $\mathbf{B}=$ whole blood \\
\hline & $\mathbf{S}=$ serum \\
\hline & $\mathbf{P}=$ plasma \\
\hline & $\mathbf{U}=$ urine \\
\hline & $\mathrm{C}=$ cerebrospinal filuid \\
\hline & $\mathbf{O}=$ other fluids \\
\hline $21-22$ & Blanks \\
\hline 23-49 & Test affected and effect \\
\hline & Inc $=$ increased \\
\hline & Dec $=$ decreased \\
\hline & $\mathbf{Z}=$ no effect \\
\hline 50 & Code for type of interactions \\
\hline & $\mathrm{V}=$ physiologicalor pharmacological \\
\hline & $\mathbf{M}=$ methodological \\
\hline & $\mathbf{N}=$ if method in use at NIH affected \\
\hline $51-54$ & Blanks \\
\hline $55-107$ & Mechanism of interaction \\
\hline $108-111$ & $\begin{array}{l}\text { Number of article describing this interaction in } \\
\text { reference file }\end{array}$ \\
\hline $112-116$ & Blanks \\
\hline $117-120$ & Number code for test at NIH \\
\hline
\end{tabular}

Table Line structure

If one of the laboratory staff or a clinician wishes to know the effects of acetophenetidin on laboratory tests he types the character string 'Acetophenetidin' into the computer at one of the terminals and all lines containing this word, ie, all the effects of the drug, are printed. Similarly the character string that is entered could be a test, eg, sodium, a test on a particular type of sample, eg, $U$ sodium (for urinary sodium), an effect on a particular test, eg, U sodium inc' (for increased excretion of urinary sodium) or a particular analytical method. If Folin-Ciocalteu is entered all methodological interferences involving the use of the Folin-Ciocalteu reagent are listed. Part of this listing is illustrated in Figure 1. By entering the name of a drug and a description of a laboratory test in a defined manner it is possible to determine if an interaction exists as the line containing the combination will be printed. Physiological or pharmacological side effects of drugs may be listed by entering key words such as 'cholestatic' or 'nephrotoxic', in which case all lines listing drugs which produce such effects are printed. All the effects cited in a single reference may be listed by entering the appropriate reference number, eg, R332. In each of the above examples all lines containing the entered character string, and therefore all drug/test interactions involved will be printed at the user's terminal.

\section{Subfile Structure}

This ability to search for character strings has been used to set up a cross correlation subfile of proprietary and generic names of drugs. All effects of drugs are entered according to the generic name of the drug. In one of the subfiles the generic name of the drug is followed by the common proprietary names. For several common over-the-counter preparations containing more than one generic compound the trade name is listed after each of the appropriate generic names. Thus 'empirin' is contained in the entries for acetophenetidin, acetylsalicylic acid, and caffeine. If a user requests a search on the basis of a proprietary name, the system responds with the line containing the generic name as the first entry with all the proprietary names appended. The user can then request a second search based on the generic name. When many drugs of similar pharmacological action are present in the file another entry is included in which the class of compound, eg, diuretic, is followed by all the appropriate generic names of the drugs in this class. Common effects of diuretics may then be listed by entering DIURETICS as the character string.

The search attribute has also been incorporated into a reference subfile. Each drug/test interaction in our system has been documented by a three-line reference entry. The first line contains the authors' names, the second the title of the article, and the third the journal, volume, and initial page numbers and the year of publication. Each line is preceded by the code number for that reference. Thus when the user requests a search for that reference code number 
ACETOPHENETIDIN ACETYLGLUCOSAMINE ACETYLSALICYLIC AC AMINOSALICYLIC AC ASCORBIC ACID ASCORBIC ACID CHLORPROMAZINE CYSTEINE DITHIOTHREITOL EPINEPHRINE ERYTHROMYCIN GALACTOSAMINE GLUCOSAMINE GLUTATHIONE GUANINE INDOLE LIDOCAINE MORPHINE

NALORPHINE OXYTETRACYCLINE PENICILLIN PHENOTHIAZINES PHENYLTHIOUREA PROCAINE SODIUM BISULFITE STRE PTOMYCIN SULFADIAZINE SULFAGUANIDINE SULFAMERAZINE SULFANILAMIDE SULFONAMIDES TETRACAINE TETRACYCLINE THIAMYL SODIUM THIOUREA TRYPTOPHAN TYROSINE URIC ACID XANTHINE
PROTEIN INC PROTEIN INC PROTEIN INC PROTEIN INC PROTEIN $z$ PROTEIN INC PROTEIN INC PROTEIN INC PROTEIN INC PROTEIN INC PROTEIN $Z$ PROTEIN INC PROTEIN INC PROTEIN INC PROTEIN INC PROTEIN INC PROTEIN INC PROTEIN INC PROTEIN INC PROTEIN INC PROTEIN INC PROTEIN INC PROTEIN INC PROTEIN INC PROTEIN INC PROTEIN INC PROTEIN INC PROTEIN INC PROTEIN INC PROTEIN INC PROTEIN INC PROTEIN INC PROTEIN INC PROTEIN INC PROTEIN INC PROTEIN INC PROTEIN INC PROTEIN INC PROTEIN INC
REACTS AS IF PHENOL WITH FOLIN-CIOCALTEU REAGENT SLIGHT REACTION WITH FOLIN-CIOCALTEU REAGENT FALSE POSITIVE WITH FOLIN-CIOCALTEU REAGENT REACTS AS PHENOL IF FOLIN-CIOCALTEU REACTION USED NO EFFECT ON FOLIN-CIOCALTEU PROCEDURE REACTS WITH FOLIN-CIOCALTEU OF LOWRY PROCEDURE REACTS AS IF PHENOL WITH FOLIN-CIOCALTEU REAGENT REACTS WITH FOLIN-CIOCALTEU OF LOWRY PROCEDURE REACTS WITH FOLIN-CIOCALTEU OF LOWRY PROCEDURE REACTS WITH FOLIN-CIOCALTEU OF LOWRY PROCEDURE NO EFFECT ON FOLIN-CIOCALTEU PROCEDURE REACTS WITH FOLIN-CIOCALTEU OF LOWRY METHOD REACTS WITH FOLIN-CIOCALTEU OF LOWRY METHOD REDUCED FORM REACTS WITH FOLIN-CIOCALTEU REAGENT REACTS WITH FOLIN-CIOCALTEU OF LOWRY METHOD REACTS WITH FOLIN-CIOCALTEU OF LOWRY METHOD REACTS WITH FOLIN-CIOCALTEU REAGENT

REACTS WITH FOLIN-CIOCALTEU OF LOWRY METHOD REACTS WITH FOLIN-CIOCALTEU OF LOWRY METHOD REACTS AS IF PHENOL WITH FOLIN-CIOCALTEU PROCEDURE REACTS AS IF PHENOL WITH FOLIN-CIOCALTEU PROCEDURE FALSE POSITIVE WITH FOLIN-CIOCALTEU REAGENT REACTS WITH FOLIN-CIOCALTEU OF LOWRY METHOD INTERFERES WITH FOLIN-CIOCALTEU REAGENT AT CONC HIGHER THAN $0.01 \%$ AFFECTS FOLIN-CIOCALTEU REACTS AS PHENOL IF FOLIN-CIOCALTEU REACTION USED REACTS AS IF PHENOL WITH FOLIN-CIOCALTEU PROCEDURE REACTS AS IF PHENOL WITH FOLIN-CIOCALTEU PROCEDURE REACTS AS IF PHENOL WITH FOLIN-CIOCALTEU PROCEDURE REACTS AS IF PHENOL WITH FOLIN-CIOCALTEU PROCEDURE REACTS AS PHENOL WITH FOLIN-CIOCALTEU REAGENT INTERFERES WITH FOLIN-CIOCALTEU REAGENT REACTS AS IF PHENOL WITH FOLIN-CIOCALTEU PROCEDURE REACTS WITH FOLIN-CIOCALTEU OF LOWRY METHOD REACTS WITH FOLIN-CIOCALTEU OF LOWRY METHOD INTERFERES WITH FOLIN-CIOCALTEU REAGENT REACTS AS IF PHENOL WITH FOLIN-CIOCALTEU PROCEDURE REACTS WITH FOLIN-CIOCALTEU OF LOWRY METHOD REACTS WITH FOLIN-CIOCALTEU OF LOWRY METHOD
R13 $\frac{\Omega}{\overline{9}}$ R97 R175类 R13 R 17 度 R93 Rl3 R93 जे R93 R93 R17 R97 के R97 R970 R97 R97 R235 R93 R1750 R179 R23응 R97 R23 $\mathrm{R} 93^{\circ}-$ R13R1780 R1798 R1755 R17\% Rl3 R235 R175 R97\$ R973 R17耏

Fig. 1 Retrieval based on Folin-Ciocalteu. ' $T$ ' in the sample-type column indicates that test conditions have been used study the effect of a compound on the Lowry procedure. The results are not necessarily applicable to physiological samplefs.

DRUG INTERFERENCES - REFERENCES

0001 WIRTH WA, THOMPSON RL,

THE EFFECTS OF VARIOUS CONDITIONS AND SUBSTANCES ON THE RESULTS OF LABORATORY PROCEDURES AMER. J. CLIN. PATH., YOL 43; 579, (1965)

MEYLER L ET AL, EDS.

EXCERPTA MEDICA FOUNDATION, SIDE EFFECTS OF DRUGS, VOL 5 ,

MOUTON \& CO., THE HAC

DRUG INDUCED MODIFICATIONS OF LABORATORY TEST VALUES,

ANON

AMER. J. HOSP. PHARM. VOL $25,238,485$, (1968)

AMERICAN HOSPITAL FORMULARY SERVICE,

ANON

AMERICAN SOCIETY OF HOSPITAL PHARMACISTS, WASH, O.C.

THE MEDICAL LETTER OH DRUGS AND THERAPEUTICS, VOL 9; 15, ISSUE 223 (JULY 1967), DRUG AND THERAPEUTIC INFORMATION INC. NEW YORK, N Y , 1967

HIIFF BB ET AL

DEX REFERENCE TO PHARMACEUTICAL SPECIALTIES AND BIOLOGICALS, 22ND ED. MEDICAL ECOND

ARTIFICIALLY ELEVATED SERUM ALKALINE PHOSPHATASE, NEW ENGL.J. MED, YOL 282; 361 (1970)

NEALE FC, BLUBB JS, POSEN S.

ARTIFACTUAL ELEVATION IN SERUM ALKALINE PHOSPHATASE CONCENTRATION AUSTR. MED. J., VOL 2; 684 (1963)

BARK CJ,

ARTIFACTUAL ELEVATION OF SERUM ALKALINE PHOSPHATASE FOLLOWING ALBUMIN INFUSIONS, ANON AMER. J. CLIN. PATH. VOL 52; 466 (1969)

ISAL LETTER ON DRUGS AND THERAPEUTICS VOL $9 ; 20$, ISSUE 228,1967

DRUG AND THERAPEUTIC INFORMATION INC., NEW YORK, N.Y., 1965,

GOODMAN LS, GILMAN A

THE PHARMACOLOGICAL BASIS OF THERAPEUTICS, 4TH ED.

MACMILLAN CO. NEW YORK, N.Y., 1970

UBRAN M

THE EFFECTS OF DRUGS ON LABORATGRY VALUES,

MEDICAL CLINICS OF N. AMERICA VOL 53; 211 (1969)

NOERMAN FW JR.

CRUG INTERFERENCE IN CLINICAL BIOCHEMISTRY

CRC CRITICAL REV. IN CLIN. LAB. SCI. 427 (i970)

CARAWAY WT,

CHEMICAL AND DIAGNOSTIC SPECIFICITY OF LABORATORY TESTS

AMER. J. CLIN. PATH. VOL 37; 445 (1962

DIAGNOSTIC BIOCHEMISTRY

MCGRAW HILL, NEW YORK, N.Y., (1969)

Fig. 2 Entries from reference file.

Each entry contains the common number for author, title of article, and journal so that all three items will be listed when the one reference number is entered. 
the three appropriate lines are returned. Examples of reference entries are illustrated in Figure 2. As it has been necessary to make some entries in code form and to abbreviate some test descriptions, another subfile of short forms has been created so that users unfamiliar with the abbreviations may obtain complete information.

\section{Operation of the System}

This system currently functions on the NIH timeshared IBM $360 / 65$ computer with a capacity of over 100 simultaneous users. It requires 13 seconds of computer time to search the entire 10000 line drug/ test interaction file for a particular test string. If the character subfile to be searched is specified, the search time can be markedly reduced. Access to the system is gained through the use of a set of authorized initials to designate the operator of a terminal and then by using an appropriate keyword. At that point the file description must also be entered to define whether the main file is to be used or the reference or short-form files.

New entries may be added to the existing files at any time. The entries do not have to be alphabetized although the search time is reduced when all entries related to one drug are together. Existing entries may be overwritten to update or correct the original information as more complete information becomes available. Theoretically any user can update, or add to, the file from his own terminal. However, we have restricted access to the system to ensure that the existing files are not altered and that no inappropriate information is entered.

\section{Discussion}

There are several ways in which drugs may affect laboratory tests. Physiological processes may be modified thereby altering the concentration of constituents in body fluids. A pathophysiological process, occurring secondary to a particular disease, may be modified by therapy. Diseases may alter the metabolism of drugs so that effects produced in normal individuals occur with increased magnitude and/or new effects may occur. Drugs or their metabolites may be measured as analytes by various chemical methods or interfere with the analytical method.

More than nine drug/test combinations are possible according to our system of entries. A drug may have a 'physiological' or 'pathophysiological' effect that increases or decreases the concentration of a test constituent, or it may have no effect on the concentration of the constituent. Drugs may increase or decrease the apparent concentration of a constituent as determined by the analytical method in use in our laboratory, or by methods in use in other laboratories. Separate entries are made for our routine methods and those in use elsewhere. For those methods which are not known to be influenced by particular drugs specific separate entries are also made.

We have included in the file apparently contradictory information when the information has been substantiated by publication, although we have not confirmed the effects ourselves. We prefer to think of the file as a mechanism to alert clinicians and clinical pathologists to possible complications rather than a literal explanation of what happens when a drug is given to a patient. The file includes both the effects anticipated when a drug is given to a patient as well as the untoward effects to which a physician should be alerted to modify or stop treatment. At present we have not tried to delineate the quantitative effects of most drugs on laboratory tests, partly because little of this information has been recorded, but also because of the great variation in response to the same dose exhibited by different individuals.

The file includes several tests, such as flocculation tests, that are no longer performed in most large laboratories, but we have included them to provide as broad a base of information as possible. We have also included many tests that cannot yet be considered routine in hospital laboratories. Several entries have also been made of conditions that may affect tests that should be considered when hospital patients or outpatients are studied. In this category we include the heading of intramuscular injections, haemolysis of samples, foods, and exercise. We intend to add the effects of diurnal variation, pregnancy, altitude, seasonal variation, age and sex differences.

The majority of the effects listed (more than $80 \%$ ) are concerned with in-vivo effects and less than $20 \%$ are concerned with analytical methods. Under the category of analytical influences, we include the effects of organic iodides on PBI measurements and any unusual colour of urine due to drugs or their metabolites. With the introduction of mechanized analytical methods specific for constituents such as glucose and uric acid that are measured frequently in the clinical laboratory the number of chemical interferences will be reduced further. The uricase procedure for uric acid is much less influenced by drugs than the more commonly used methods in which reducing substances are measured (Gochman and Schmitz, 1971).

The computer file has been used extensively by the staff of the Clinical Pathology Department to assist in the interpretation of, in most cases, unexpected changes in test values without a corresponding 
change in the clinical condition of patients. It has assisted physicians in planning study procedures so that these may be performed at a time when interactions between drugs and tests would not arise. We have avoided considering the effect of drugs upon the action of other drugs in the present system except in so far as they may influence the action of anticoagulants on the prothrombin time.

The file has been modified so that it also exists in the departmental CDC-3200 computer where it is being used on a pilot basis to provide automatic interpretation of data from one nursing unit. Both information on drugs and on tests requested is entered into the computer which generates an interpretative report on each patient. An analysis of this experiment will be published at a later date.

Although several publications concerning drug/ test interactions have appeared recently, only a computer-based file of the type described here permits the rapid identification of those tests which are affected by a drug as well as listing those drugs that affect a particular test. The critical differentiation between physiological and analytical effects has not been made in several publications. Our laboratory-orientated file allows clinical pathologists another avenue for increased participation in improving the care of patients. Widespread use of $\bar{T}$ such a system should reduce the incidence of misinterpretation of laboratory results, especially when $\underline{\underline{O}}$

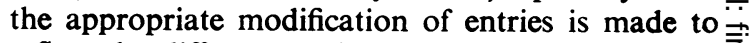
reflect the different analytical procedures in use in $\stackrel{\vec{P}}{+}$ clinical laboratories.

We intend to publish the information contained in the files and to update the files as new effects are $\frac{\bar{s}}{\frac{1}{\sigma}}$ identified. We would be pleased to receive reports $\stackrel{\varnothing}{\varrho}$ of drug/test interactions observed by physicians to maintain our files up to date, and to assist in the dissemination of such information.

References

Garb, S. (1971). Clinical Guide to Undesirable Drug Interactions and Interferences. Springer, New York.

Gochman, N., and Schmitz, J. M. (1971). Automated determination Nu of uric acid, with use of a uricase-peroxidase system. Clin. G Chem., 17, 1154-1159.

Hansten, P. D. (1971). Drug Interactions, pp. 437. Lea and Febiger, $\overrightarrow{\vec{\theta}}$ Philadelphia.

Martin, E. W. (1971). Hazards of Medication. Lippincott, Phila- $\stackrel{\infty}{+}$ delphia.

Melmon, K. L. (1971). Preventable drug reactions-causes and cures. New Engl. J. Med., 284, 1361-1368.

Van Peenen, H. J., and Files, J. B. (1969). The effect of medication $Z$ on laboratory test results. Amer. J. clin. Path., 52, 666-670.

Young, D. S., Harris, E. K., and Cotlove, E. (1971). Biological and $₫$ analytic components of variation in long-term studies of serum constituents in normal subjects. IV. Results of a study designed to eliminate long-term analytic deviations. Clin. Chem., 17, 403-410. 